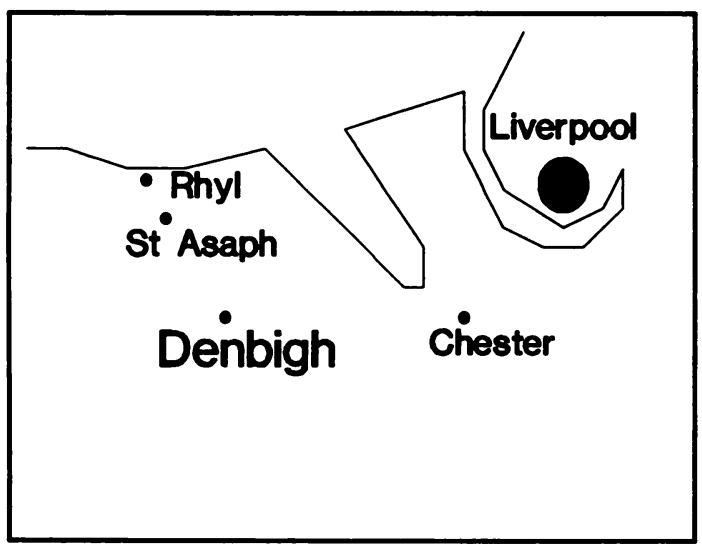

College of North Wales, Bangor, and the North Wales Institute of Higher Education, Wrexham. A traditional association with the Department of Psychiatry, University of Liverpool is also being maintained and strengthened.

\section{Future of psychological medicine}

Professor Michael Shepherd, Institute of Psychiatry, London, gave the inaugural lecture: 'Psychological Medicine: Past Imperfect, Future Conditional'.

Professor Shepherd began by outlining how the decline of the mental hospital, the patent deficiencies of most community-care programmes and the crisis in the Health Service had combined to raise questions about the future prospects of psychiatry. An overview of psychiatry's post-war evolution indicated why traditional theory and practice were proving inadequate to meet current demands and to sustain an effective professional identity.

Professor Shepherd stressed that the relatively small proportion of medically qualified research workers tackling mental health topics also gave cause for concern. But his main conclusion was that the growing claims of other disciplines, non-medical as well as medical, on the subject matter of psychiatry will be irresistible without a broadening of the education, outlook and function of its practitioners.

- Dr Wilkinson has been promoted to Reader in Psychological Medicine as from I December 1990.

\title{
William Cullen's bicentenary
}

\section{R. E. Kendell, Professor of Psychiatry, University of Edinburgh}

William Cullen (1710-1790) was the greatest teacher of clinical medicine in Britain in the 18th century. He was born in Hamilton in Lanarkshire and began his career in Glasgow where he held the chair of chemistry and was one of the founders of the medical school. In 1755 he moved to Edinburgh with its already flourishing medical school and its new hospital, the Royal Infirmary, and there he held in succession the chairs of chemistry, the institutes (theory) of medicine and the practice of physic. Together with Alexander Monroe he made Edinburgh the most famous medical school in the Western world and students came from far and wide to be taught by him - from England, Scotland and Ireland, from the Americas and the West Indies and from the Continent. Like Boerhaave, his reputation rested mainly on his gifts as a teacher and it is clear that his students idolised him. Benjamin Rush, the founder of the first medical school in the New World in Philadelphia, America's first psychiatrist and one of the signatories of the American Declaration of Independence, wrote of him that "It is scarcely possible to do justice to this great man's Character either as a scholar, a physician, or a Man".

Although Cullen wrote widely on many subjects from the chemistry of crystalline solids to materia medica, he is of interest to psychiatrists mainly because it was he who coined the term neurosis. Cullen believed that excesses or deficiencies, local or general, of "nervous energy" were the root cause of most disease and in the elaborately tiered nosology of disease he published in 1769 neuroses were one of the four Linnean orders he recognised. Although his neuroses encompassed what we would now regard as neurological, neurotic and psychotic disorders, and included hysteria, hypochondriasis, convulsions, apoplexy and the vesaniae (an old Roman term for insanity), it also embraced many other conditions which we now regard as quite unrelated, like dyspnoea, diabetes, pertussis, tetanus and cholera. Cullen's over elaborate classification of disease did not long survive his death, but his term neurosis remained in use throughout the 19th century as a convenient title for an ill defined group of 'nervous' 
disorders like hysteria, hypochondriasis and neurasthenia, and was then adopted and immortalised by Sigmund Freud and the infant school of psychoanalysis at the beginning of this century.

The Royal College of Physicians of Edinburgh held a two day symposium, on 24 and 25 August 1990 , to mark the bicentenary of Cullen's death. A series of ten lectures were given over the two days by distinguished medical historians from the United States, Canada and England and by members of the Edinburgh College of Physicians and the Edinburgh Medical School. They covered many different aspects of Cullen's career and the development and influence of Edinburgh medicine in the 18th century, and despite being held in the middle of the Edinburgh Festival and the holiday season the symposium was remarkably well attended. It was also fascinating to observe the contrast between the professional historians and the doctors. The latter were largely concerned with Cullen's ideas and teaching in relation to contemporary medicine, the developments he anticipated and those he failed to anticipate. The historians, on the other hand, were more concerned with the broader social and political climate in which Cullen was operating and the medical school developing then but the two approaches complemented one another very well. There was also a well laid out exhibition of books,

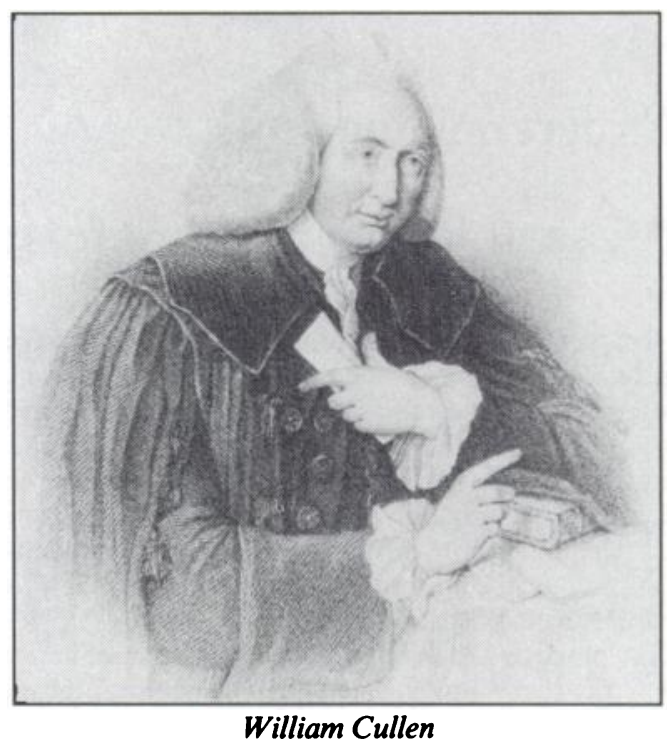

documents and engravingsillustrating Cullen'scareer and the early years of the medical school and the Royal Infirmary which was open to the public throughout the week.

\section{The application of resource management in the Special Hospitals Service Authority}

\section{A pilot study at Rampton Hospital}

The Special Hospitals Service Authority (SHSA) has commissed KPMG Peat Marwick McLintock Management Consultants to lead a pilot study to identify how the application of resource management (RM) techniques can best be introduced to the overall benefit of the management of a Special Hospital. The study is to be based at Rampton Hospital. The KPMG staff will work closely with a Project Team comprised of the hospital's staff.

The initiatives associated with the introduction of RM within the NHS have, to date, largely been concentrated in the acute hospital sector, initially at selected pilot sites and currently through the 'rollout' programme supported by the RM Directorate. However, the SHSA feels that, given the objectives, there is no reason to suppose that the Special Hospitals Service cannot benefit from participating in this initiative providing that its unique circumstances are fully appreciated. However, this study could lead the way for the development of RM in psychiatric services in general.

Roger Hinton, Capital Resources Manager at the SHSA says, "The investigation of RM techniques is one of a portfolio of management initiatives being introduced to our Hospitals. Peat's experience in the RM field and the changes being effected by Diana Dickens the UGM and her team combine to create an excellent environment for the study".

For further information contact Charles Kaye, Chief Executive or Roger Hinton at the SHSA (telephone 071609 9700); Barrie Woodcock (Partner) or Jane Finlan, KPMG Birmingham (telephone 021233 1666); Dr Diana Dickens, Rampton Hospital (telephone 0777 84321). 